\title{
A Study of Resilience amongst people who have lost their relatives in a natural calamity: a study from Uttarakhand in Northern India
}

\author{
Chetan Lokhande ${ }^{1}$, Nilesh Mohite ${ }^{2}$, Reetika Dikshit ${ }^{3}$, Pragya Lodha ${ }^{4}$, Avinash De Sousa ${ }^{5}$, \\ Nilesh Shah ${ }^{6}$ \\ ${ }^{1}$ Resident Doctor, \\ ${ }^{2}$ Resident Doctor, Department of Psychiatry, Government Medical College, Tezpur, Assam. \\ ${ }^{3}$ Specialty Medical Officer \\ ${ }^{4}$ Research Assistant, De Sousa Foundation, Mumbai. \\ ${ }^{5}$ Research Associate \\ ${ }^{6}$ Professor and Head \\ 1,3,5,6 Department of Psychiatry, Lokmanya Tilak Municipal Medical College, Mumbai.
}

Corresponding author: Reetika Dikshit

Email-reetikadikshit@yahoo.com

\begin{abstract}
Background and Objectives: Natural disasters can be a devastating experience for anyone. Mental disorders are common amongst survivors of natural disasters. Resilience is a significant factor that helps these survivors overcome this traumatic episode. In this study, we attempt to examine whether the level of resilience differs with nature of loss, in this case a natural calamity. Resilience is one attribute that helps an individual recover from a disastrous event and allows them to bounce back. It may determine the level of psychological stress in an individual because resilience is in fact a protective factor and individual with high resilience may have lesser degree of psychological stress. Resilience's has a strong neurobiological basis and also independent psychobiological construct.

Methods: Trained research officers in mental health from Mumbai went and stayed in the affected region and arranged for local psychiatric help prior to starting the study. Consenting subjects participated. Clinical details, level of resilience; psychological stress, life events and effect of trauma were assessed between two groups of subjects.

Results: The level of resilience was low and closely related to psychopathology in both the group of survivors. Individuals who had lost their relatives showed relatively very poor resilience, (CD-RISK 20.61 (SD 8.33) vs. 40.57 (SD 13), $\mathrm{p}=>0.01$ ); had high levels of stress (GHQ, 27.44 (SD 3.82) vs. 23.36 (SD 5.44), $\mathrm{p}=0.001)$. Need for high social support $(11$ (SD 30.5) vs. 2 (SD 7.1) p=0.021) did not express any significantly higher requirement for financial support. Level of resilience was negatively correlated with experience of adverse life event in previous year and number of relatives lost.

Conclusion: Resilience is a personal characteristic, which is severely affected with experience of disaster. Individuals who were already vulnerable suffered the most. People who had lost relatives showed very poor level of personal strength and need for better social support and specific psychological intervention.
\end{abstract}

Keywords: Resilience, trauma, disaster, death, relatives.

(Paper received $-10^{\text {th }}$ May 2018, Peer review completed $-20^{\text {th }}$ June 2018)

(Accepted $-27^{\text {th }}$ June 2018) 


\section{INTRODUCTION}

Resilience is defined as the ability of individuals to bounce back after trauma and return to their previous psychological selves [1]. Resilience is a construct that has huge ramifications and has biological and psychological factors that affect it [2]. It is also a marker of psychopathology in various disorders and plays a role in the recovery from trauma and stressful events [3]. Cohesive communities, family systems, social support and religious faith and spirituality are factors that help survivors cope during a disaster but the loss of a family member has grave implications for recovery from trauma [4]. It is well known that resilience differs from recover in trauma and that there are multiple pathways that leads to resilience and recovery in trauma. A number of factors affect the development of resilience which includes displacement of the family or home, financial losses, death of a loved one, culture, religion, defenses at play and pessimism in the wake of trauma.

Sudden death of a loved one can be emotionally devastating, unexpected deaths provoke especially strong responses, as there is less time to prepare for and adapt to the death [5]. The unexpected death of a loved one is associated with the development of depression and anxiety symptoms, substance use, and other psychiatric disorders and with heightened risk for prolonged grief reactions [6]. The impact of unexpected death in the general population in the wake of trauma remains understudied. There are unresolved issues regarding the association between unexpected death and psychiatric morbidity and whether certain disorders are more likely than others to occur in the wake of a loved one's death [7]. It is also unknown whether death has associations with mental disorders at different points across the life course, and whether a greater number of unexpected death experiences is associated with more episodes of psychiatric disorders. This when complicated by the wake of trauma has far reaching implications [8].

\section{Context of the Paper}

The combination of cloud bursts, floods, and landslides triggered on 16 and 17 June 2013 affected most of the 13 districts in Uttarakhand. Magnitude of the disaster prompted people to coin the term Himalayan tsunami for this disaster. Worst hit places were very important Hindu pilgrimage districts namely Rudraprayag, Chamoli, Uttarakashi, and Pithoragarh. We at the Department of Psychiatry, Lokmanya Tilak Municipal Medical College, Mumbai decided to coordinate some psychosocial relief in this Himalayan tsunami affected region. Accordingly, a multidisciplinary team was deputed to Uttarakhand with the mandate of identifying and treating persons needing immediate interventions and for assessing psychiatric/psychosocial morbidity. The data presented in this study is a part of the assessment and intervention during the emergency relief work. Ethical clearance was obtained for the manuscript from the Ethics Committee at our hospital.

\section{METHODOLOGY}

The disaster management team undertook observation mainly in the worst affected two districts (Rudraprayag and Uttarakashi). The team worked for nearly 4 weeks providing mental health care. Assessments were done considering accessibility and representation ability of the affected population. The assessed population included pilgrims visiting the holy places of Uttarakhand from various parts of India and local population who lived in these areas.

This disaster was unique as substantial proportions of the affected population were pilgrims. The team visited the affected district hospital, primary health centers (PHCs), evacuation centers, relief camps, schools and also communities (visiting the affected villages, which were inaccessible by road). The team used to approach the medical officer in charge with the request to make an announcement to availability of mental health professionals and that the needy could avail clinical services. The community leaders and local staff announced the availability of mental health professionals. While doing so, they used to give descriptions of common symptoms of psychopathology. During the consultations with the survivors, attempts were also made to identify other cases using the snowball technique.

Qualified psychiatrists diagnosed the patients using the International Classification of Diseases-10 criteria (WHO, 1992) [9]. Informed oral consent was obtained from all the subjects. They also interviewed all 
subjects and were supported by psychologists and social workers. Workers from local NGOs helped the psychiatrists where language was an issue. Two groups of subjects were chosen for the study. One was a group that went through the trauma and did not lose a family. The second was a group that lost a family member and loved one in the trauma. Both these groups were assessed using clinical assessment for psychopathology and they were then administered the following scales to assess the impact of trauma -

1. General Health Questionnaire-30 (GHQ-30) - It is a screening device for identifying minor psychiatric disorders in the general population and within community or non-psychiatric clinical settings such as primary care or general medical out-patients. Suitable for all ages from adolescent upwards and not children, it assesses the respondent's current state and asks if that differs from his or her usual state. It is therefore sensitive to short-term psychiatric disorders but not long-standing attributes of the respondent. The scale is made up of 30 items where issues related to physical illness are not assessed [10].

2. The Connor-Davidson Resilience Scale (CDRS) - The scale comprises of 25 items, each rated on a 5-point scale (0-4), with higher scores reflecting greater resilience. The scale has been administered to subjects in community samples, primary care outpatients, general psychiatric outpatients, clinical trials of generalized anxiety disorder and PTSD. The scale has demonstrated good psychometric properties [11].

3. The Impact of Events Scale (IES) - The Impact of Events Scale has become one of the most widely used instruments in the assessment of post-traumatic stress reactions in adults. The original IES comprised two subscales: intrusion (the sum of seven items), and avoidance (the sum of eight items) that mapped on to what was described in the B and C criteria of the diagnosis of PTSD, the signs and symptoms of intrusive cognitions and affects together or oscillating with periods of avoidance, denial, or blocking of thoughts and images. The scale used a somewhat unusual response format: Not at all $=0$, Rarely $=1$, Sometimes $=3$, and Often $=5[12]$.

\section{STATISTICAL ANALYSIS}

The data was analyzed using computerized statistical software SPSS Version 18.0. The categorical data was analyzed using the unpaired $t$ test, Chi square test and one-way ANOVA where appropriate and Pearson's correlation was used to assess the correlation between different scales used in the study.

\section{RESULTS}

Table 1 - Sociodemographic Parameters

\begin{tabular}{|c|c|c|c|}
\hline Parameters & Index & Control & p Value \\
\hline Age & $38.89(11.6)$ & $43.2(12.8)$ & 0.16 \\
\hline Male & $\begin{array}{c}10 \\
(27.7 \%)\end{array}$ & $16(57.1 \%)$ & 0.018 \\
\hline Female & $28(72.2 \%)$ & $12(42.8 \%)$ & \\
\hline Education (years of study) & $5.0(5.3)$ & $7.6(5.6)$ & 0.065 \\
\hline Marital status-married & $21(58.3 \%)$ & $20(71.4 \%)$ & 0.121 \\
\hline Living alone & $1(2.7 \%)$ & $2(7.1 \%)$ & \\
\hline With spouse & $20(55.5 \%)$ & $20(71.4 \%)$ & 0.121 \\
\hline Socioeconomic class-lower & $27(75 \%)$ & $20(71.4 \%)$ & 0.74 \\
\hline Presence of addiction & $5(13.8 \%)$ & $8(28.5 \%)$ & 0.148 \\
\hline Alcohol & $3(8.33)$ & $3(10.7)$ & 0.378 \\
\hline Needs assessment & & & \\
\hline Financial & $30(83.3 \%)$ & $26(92.8 \%)$ & 0.253 \\
\hline Social & $11(30.5)$ & $2(7.1$ & 0.021 \\
\hline
\end{tabular}




\begin{tabular}{|c|c|c|c|c|}
\hline & $\begin{array}{c}\text { Medical } \\
\text { rehabilitation }\end{array}$ & $27(75 \%)$ & $18(64.2)$ & 0.352 \\
\hline Basic & $2(5.56)$ & $7(25 \%)$ & 0.026 \\
\hline GHQ scores & $27.44(3.82)$ & $\begin{array}{c}23.36 \\
(5.44)\end{array}$ & 0.001 \\
\hline LEQ-last year & $4.4(1.59)$ & $4.11(2.14)$ & 0.473 \\
\hline CD-RISK & $20.61(8.33)$ & $40.57(13)$ & $<0.01$ \\
\hline
\end{tabular}

Table 2 - Correlation Tables

\begin{tabular}{|c|c|c|c|c|c|c|c|c|}
\hline \multirow[t]{2}{*}{$\begin{array}{l}\text { Parameters } \\
(\mathrm{n}=64)\end{array}$} & \multicolumn{2}{|c|}{ GHQ } & \multicolumn{2}{|c|}{ LEQ } & \multicolumn{2}{|c|}{ CD-RISK } & \multicolumn{2}{|c|}{$\begin{array}{l}\text { Number of } \\
\text { relatives lost }\end{array}$} \\
\hline & $\mathbf{R}$ & $\mathbf{P}$ & $\mathbf{R}$ & $\mathbf{P}$ & $\mathbf{R}$ & $\mathbf{P}$ & $\mathbf{R}$ & $\mathrm{P}$ \\
\hline GHQ & 1 & & 0.342 & 0.006 & -625 & 0 & $0.381^{* *}$ & 0.002 \\
\hline $\begin{array}{l}\text { LEQ } \\
\end{array}$ & $0.342^{* *}$ & 0.006 & 1 & & $-0.266^{*}$ & 0.033 & 0.05 & 0.692 \\
\hline CD-RISK & $-0.625^{* *}$ & 0 & $-0.266^{*}$ & 0.033 & 1 & & -0.73 & 0 \\
\hline $\begin{array}{l}\text { Number of } \\
\text { relatives lost }\end{array}$ & 0.381 & 0.002 & 0.05 & 0.692 & $-0.672^{* *}$ & 0 & 1 & 0 \\
\hline
\end{tabular}

As expected the victims had high level of stress and much more among people who lost their relative. Significantly more victims who had lost their relatives due to death expressed need for help for basic requirements of life and for social support. Financial requirement for rehabilitation were not a priority. Though level of resilience was very poor in both group of sufferers, people who lost their relatives showed very poor resilience, almost half than people who had not lost their relatives.

\section{DISCUSSION}

There is no person or place immune from disasters or disaster-related losses. In addition to natural hazards, disease outbreaks, acts of terrorism, social unrest, or financial disasters- they all can lead to large-scale consequences and psychological stress for affected people and the nation, overall. Psychological stress is inversely proportional to resilience [13-14]. Greater the resilience, lower is the psychological stress and vice versa.

The Himalayan tsunami that struck the state of Uttarakhand was marked as the worst form of natural disaster in our country after the Tsunami of 2004. The present research was conducted to study the level of resilience amongst the people who were affected by this calamity- comparing the levels of resilience among people who had lost their relatives and those who had not. It was hypothesized that that people who have lost their relatives may have much lower resilience than those who have not. It was further hypothesized that the level of resilience among people who have faced the natural calamity will have more severe psychological stress after considerable period of time [15].

The team providing emergency relief work studied a sample of 80 people- under this the GHQ-30, CDRS and IES were administered. The assessed population included pilgrims visiting the holy places of Uttarakhand- Rudraprayag and Uttarakashi. These people came from various parts of India and the local population who lived in these areas. Of these 80, 16 people did not complete the questionnaires. Consequently, 64 people were retained to study. 36 samples were retained in the control group (people those who did not lose their relatives) \& 28 samples were remaining in the study (index) group (people who lost their relatives). The data was analysed using unpaired $t$ test, Chi square test and one-way ANOVA and Pearson's correlation, relevant to derive results. The findings were in line with the hypotheses as the victims who had lost their relatives to the landslide, had higher levels of stress- almost half than people who had not lost their relatives; as compared to those who had not lost their relatives. The basis for this finding being the scores on GHQ-30. Furthermore, the needs assessment showed that significantly more number of people who had lost their relatives due to death expressed need for help for basic requirements of life and for social support, over financial reimbursement [16]. 
The most important finding of the study was that no difference was found on the Impact of Events Scale. Additionally, it was also observed that the symptoms patterns for PTSD remained the same for both- study (index) and control groups-as reflected in the PTSD Symptom Questionnaire. No difference among the two groups was reported on the MADRS scale as well. Thus, no psychopathology was evidenced, however, psychological stress was identified in both groups, with implicated low resilience levels. Resilience is a strong psycho-biological marker in determining the ability to cope with stressors and recover for psychopathological conditions. The team discussed that it appeared that the resilience of the people could not become normal. Therefore, the need for social support was a natural expectation besides other factors also being responsible for such requirements. Research claims that low level of resilience is closely related to psychopathology for mental disorders, and this may possibly persist among these individuals. Mere management of mental disorders or symptoms of psychological distress is not enough and the individuals who had lost their relatives would require psychological intervention focused to re-gain their capacities of adaptations [17].

\section{CONCLUSION}

Stress is a reality of our lives however the short term and long-term effects of stress vary with the nature of trauma attached with the stressor. The level of resilience in an individual, determines the ability to withstand and cope with the stress. Resilience, where at one hand is predisposed, can largely also be developed in individuals. This can further help individuals manage psychological stress and also reduce vulnerability to possible psychopathology in the face of stress and trauma.

\section{REFERENCES}

1. Davydov DM, Stewart R, Ritchie K, Chaudieu I. Resilience and mental health. Clin Psychol Rev 2010;30(5):479-95.

2. Southwick SM, Litz BT, Charney D, Friedman MJ, editors. Resilience and mental health: Challenges across the lifespan. Cambridge University Press; 2011.

3. Rutten BP, Hammels C, Geschwind N, Menne- Lothmann C, Pishva E, Schruers K, Van Den Hove D, Kenis G, Van Os J, Wichers M. Resilience in mental health: linking psychological and neurobiological perspectives. Acta Psychiatr Scand 2013;128(1):3-20.

4. Fazel M, Reed RV, Panter-Brick C, Stein A. Mental health of displaced and refugee children resettled in highincome countries: risk and protective factors. Lancet 2012;379(9812):266-82.

5. Keyes KM, Pratt C, Galea S, McLaughlin KA, Koenen KC, Shear MK. The burden of loss: unexpected death of a loved one and psychiatric disorders across the life course in a national study. Am J Psychiatry 2014;171(8):864-71.

6. Kristensen P, Weisæth L, Heir T. Bereavement and mental health after sudden and violent losses: a review. Psychiatry: Interpers Biol Process 2012;75(1):76-97.

7. Shakespeare-Finch J, Armstrong D. Trauma type and posttrauma outcomes: Differences between survivors of motor vehicle accidents, sexual assault, and bereavement. J Loss Trauma 2010;15(2):69-82.

8. Bonanno GA, Mancini AD. Beyond resilience and PTSD: Mapping the heterogeneity of responses to potential trauma. Psychol Trauma: Theory Res Pract Policy 2012;4(1):74-9.

9. World Health Organization. International Classification of Diseases $-10^{\text {th }}$ edition ; 1992.

10. Huppert FA, Walters DE, Day N, Elliott BJ. The factor structure of the General Health Questionnaire (GHQ30): a reliability study on 6317 community residents. Br J Psychiatry 1989;155(2):178-85.

11. Connor KM, Davidson JR. Development of a new resilience scale: The Connor- Davidson resilience scale (CD- RISC). Depress Anxiety 2003;18(2):76-82.

12. McDonald AS. Factor structure of the Impact of Events Scale in a non-clinical sample. Personal Individ Diff 1997;23(3):419-24.

13. Bonanno GA. Loss, trauma, and human resilience: Have we underestimated the human capacity to thrive after extremely aversive events ?. Amer Psychol. 2004;59(1):20-8.

14. Becvar DS, editor. Handbook of family resilience. Springer Science \& Business Media; 2012.

15. Agaibi CE, Wilson JP. Trauma, PTSD, and resilience: A review of the literature. Trauma Viol Abuse 2005;6(3):195-216.

16. Connor KM, Davidson JR, Lee LC. Spirituality, resilience, and anger in survivors of violent trauma: A community survey. J Traum Stress 2003;16(5):487-94. 
17. Bonanno GA, Westphal M, Mancini AD. Resilience to loss and potential trauma. Ann Rev Clin Psychol 2011;7:511-35.

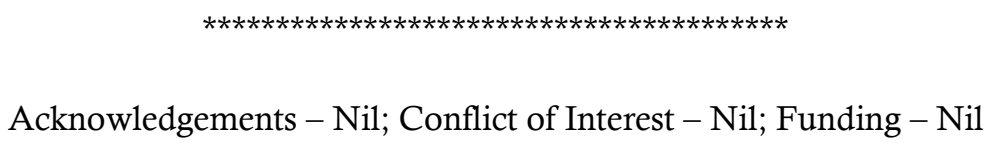

